\title{
Vazios urbanos: a não utilização dos imóveis municipais em Campina Grande e o descumprimento da função social da propriedade
}

\author{
Urban voids: the non-use of municipal properties in Campina Grande and the \\ non-fulfillment of the social function of the property
}

Gilberto Rodrigues Carneiro[a] (1), Edjane Esmerina Dias da Silva[b] (D)

[a] Universidade Estadual da Paraíba (UEPB), Campina Grande, PB, Brasil

[b] Universidade Federal de Campina Grande (UFCG), Campina Grande, PB, Brasil

Como citar: Carneiro, G. R., \& Silva, E. E. D. (2020). Vazios urbanos: a não utilização dos imóveis municipais em Campina Grande e o descumprimento da função social da propriedade. urbe. Revista Brasileira de Gestão Urbana, 12, e20190294. https://doi.org/10.1590/2175-3369.012.e20190294

\section{Resumo}

Os bens imóveis que compõem o patrimônio do Estado são instrumentos de execução de políticas públicas e devem servir à sociedade. Entretanto é extremamente comum encontrar terrenos baldios, prédios fechados ou até edifícios, todos públicos, que não utilizam o total de suas respectivas áreas. Este fato caracteriza uma verdadeira violação aos princípios constitucionais da função social da propriedade e da eficiência. Como consequência dessa malversação dos bens públicos, nasce um problema comum a grandes cidades brasileiras: os "vazios urbanos". Diante deste cenário, esta pesquisa propõe, através de um estudo de caso, investigar os desusos de imóveis públicos municipais e a mapear "vazios urbanos" no perímetro urbano do município de Campina Grande, segundo maior município do estado da Paraíba, Brasil. Como resultado desta pesquisa foram encontrados um total de 19 imóveis públicos esvaziados. A maioria destes "vazios urbanos" localizam-se em bairros periféricos, comprometendo a função social de interesse da população carente.

Palavras-chave: Administração pública. Vazios urbanos. Direito à cidade. Bens públicos. Imóveis públicos.

\section{Abstract}

The real estate that makes up the state's assets are instruments for the execution of public policies and should serve society. However, it is extremely common to find vacant lots, enclosed buildings or even public buildings that do not use the total of their respective areas. This characterizes a true violation of the constitutional principles of the social function of property and efficiency. As a consequence of this misappropriation of public goods, a common problem arises in large Brazilian cities: the "urban voids". Thus, through a case study, this research proposes to investigate the disuse of municipal public properties and to map "urban voids" in the urban perimeter of the Municipality of Campina Grande, second largest municipality of the state of Paraíba, Brazil. As a result of this search a total of 19 vacant public properties were found. Most of these "urban voids" are located in peripheral neighborhoods, compromising the social function of interest to the needy population.

Keywords: Public administration. Urban voids. Right to the city. Public goods. Public real estate.

GRC é mestre em Administração Pública, e-mail: gibarodrigues88@gmail.com

EEDS é doutora em Ciências Sociais, e-mail: edjanedias@gmail.com 


\section{Introdução}

Administrar é o termo utilizado para caracterizar ações que visam gerir bens e interesses de modo adequado. Quando estes pertencem à coletividade, é criada uma pessoa jurídica de direito público com o objetivo de fazer com que esses ativos tenham sua finalidade cumprida. Os órgãos e entidades exercem sobre os bens, sob sua responsabilidade e utilizados na persecução do interesse público, um domínio de propriedade regulado por normas de direito público, um regime jurídico diferenciado que garante várias prerrogativas e, mais ainda, deveres.

Essas prerrogativas são concedidas como forma de reforçar que sejam cumpridas as suas respectivas funções administrativas, as quais, vale destacar, são impostas por lei. Esses bens públicos, quando afetados por finalidade específica em prol da coletividade, gozam de proteção contra ações de, por exemplo, compra e venda, doação, permuta, hipoteca, penhor, etc. 0 objetivo idealizado no ordenamento jurídico é claro: garantir que esses bens sejam utilizados no cumprimento das funções sociais e econômicas do Estado. Entretanto, percebemos que, em muitos casos, a finalidade atribuída à propriedade pública não é respeitada.

Tratando especificamente do caso de imóveis, construídos ou não, localizados nos centros urbanos de grandes cidades do Brasil, um simples olhar mais investigativo é suficiente para perceber a existência de verdadeiros "vazios urbanos" representados por imóveis subutilizados, não utilizados ou desocupados. Esses bens desrespeitam o princípio constitucional da função social da propriedade.

Nesse contexto, esta pesquisa propõe, através de um estudo de caso, investigar os desusos de imóveis públicos e proceder com um mapeamento de "vazios urbanos" no perímetro urbano do município de Campina Grande, Paraíba, Brasil, buscando, especificamente: analisar as relações entre a Administração Pública e os "vazios urbanos"; categorizar esses espaços esvaziados em imóveis públicos municipais desocupados, não utilizados e subutilizados no perímetro urbano do município.

\section{Referencial teórico}

\section{Função social da propriedade pública e vazios urbanos}

Sabe-se que todo bem público, imóvel ou não, é vinculado ao cumprimento de finalidades públicas, isto é, busca dar efetividade a promoção do bem comum. Logo, é inimaginável pensar que o patrimônio público venha ser utilizado para finalidade diversa.

Di Pietro (2006) adota esse raciocínio e afirma que falar de função social da propriedade pública chega a soar como pleonasmo. Consoante entendimento da autora, no direito brasileiro, é possível perceber que a Constituição de 1988 adota, expressamente, o princípio da função social da propriedade privada e, implicitamente, com menos clareza, o princípio da função social da propriedade pública. Este pode ser deduzido de alguns dispositivos que tratam da política urbana, como o art. 182, que traz como objetivo da política de desenvolvimento urbano o pleno desenvolvimento das funções sociais da cidade e a garantia do bem-estar de seus habitantes (Brasil, 1988).

A Lei no 10257, de 10 de Julho de 2001 (Brasil, 2001), a qual recebeu a designação de Estatuto das Cidades, regulamentou os artigos 182 e 183 da Carta Magna com a finalidade de organizar o adequado aproveitamento do solo de acordo com as funções sociais da cidade e da propriedade urbana, instituindo várias diretrizes e até repetindo o texto constitucional.

É do art. 39 do Estatuto das Cidades que se retira o esclarecimento de que a função social da propriedade urbana será cumprida sempre que assegurar o atendimento das necessidades dos cidadãos quanto à qualidade de vida, à justiça social e ao desenvolvimento das atividades econômicas, sempre com a observância das diretrizes fixadas pelo Plano Diretor (Lei municipal obrigatória para cidades com mais de vinte mil habitantes) (Brasil, 2001). 
Já a Lei Complementar no 003 (Campina Grande, 2006), que trata do Plano Diretor do Município de Campina Grande, aborda a questão da gestão assegurando que serão observados os princípios fundamentais da função social da cidade e da sustentabilidade. Também apresenta previsões legais acerca do atendimento das necessidades dos cidadãos quanto à qualidade de vida, à justiça social, ao desenvolvimento das atividades econômicas e na valorização e requalificação dos espaços públicos, promovendo habitabilidade e acessibilidade para todos. Em uma leitura do referido texto legal, fica claro que o código é preocupado em ampliar os espaços públicos, reconhecendo sua importância como áreas essenciais para a expressão da vida coletiva.

Percebe-se, portanto, que a legislação brasileira, com bases estabelecidas na Constituição Federal, busca oprimir a criação de "vazios urbanos" nas cidades, forçando ao proprietário de áreas urbanas a promover sua adequada utilização e consequente cumprimento da função social.

Entretanto, este pensamento não é uníssono entre aqueles que estudam o tema. Abe (2008), a seu turno, tem como argumento principal, para descartar a aplicação do princípio da função social da propriedade sobre os bens públicos, o fato de ser impossível que se aplique sanções aos entes públicos quando estes (União, estados, DF, municípios) detiverem sob sua custódia imóveis desafetados de finalidades públicas. A Carta Magna atual traz, no art. 182, § 3ํㅡㄹ expressa vedação quanto ao usucapião de bens públicos urbanos e, em seu art. 191, parágrafo único, também veda o usucapião de propriedades localizadas em zonas rurais.

Em que pese a discussão teórica acerca do referido princípio, o fato é que, no plano do real, é extremamente comum, em grandes cidades, detectar a presença de terrenos baldios, prédios fechados ou até edifícios, públicos, que não utilizam o total de suas respectivas áreas. Por esta razão é pertinente questionar e discutir até que ponto o princípio da função social da propriedade tem sido devidamente respeitado pelo próprio poder público.

Deve-se entender que não apenas a aquisição, alienação, doação e locação fraudulenta de bens públicos realizadas de formas ilícitas acarretam danos ao erário. No momento em que o gestor público deixa de atribuir usos específicos aos bens desafetados, também temos uma malversação de recursos públicos. Imóveis que deveriam estar promovendo bem-estar coletivo ficam sujeitos ao abandono, à depredação e, ainda, importam em pesados gastos de manutenção os quais serão pagos pelos cofres públicos (Carvalho, 2012).

Não raramente, a própria Administração Pública acaba por ser a vítima da omissão de seus gestores, pois paga aluguel de bens necessários ao exercício de suas atividades, enquanto possui outros, de mesmas características, que se encontram ociosos e renegados. Outra consequência do abandono do patrimônio público é a formação de "vazios urbanos". Espaços que vão de encontro aos novos conceitos de cidades sustentáveis, inteligentes e promovedoras do bem estar social.

"Vazios urbanos" é uma terminologia que tem sido cada vez mais utilizada por pesquisadores que buscam estudar os fenômenos urbanos, suas motivações e consequências. Muitos autores, geralmente da área do urbanismo, que se preocupam com temas relacionados à cidade, promovem debates acerca de seu significado. Tendo em vista o caráter polissêmico do termo, é pertinente esclarecer o universo conceitual e de alguns significados a ele ligados.

A ideia de "vazios urbanos" passou a ser objeto de reflexões frequentes no século 19, em decorrência do grande processo de desindustrialização visualizado nas principais cidades europeias. Paris e Londres são grandes exemplos desse movimento. Precursoras do processo de industrialização, foram as primeiras a sentir o esvaziamento de áreas antigamente ocupadas pela indústria. A multiplicação de áreas como ferrovias desativadas, zonas industriais e edifícios abandonados, configuradas pela perda da função ou utilidade que antes detinham, motivou os primeiros estudos realizados pela França (1979) e Inglaterra (1982) com a elaboração de inventários que mapeavam esses espaços (Borde, 2006).

Entretanto, o que realmente constitui um "vazio urbano"? Muitos responderam essa questão de diferentes maneiras. Portas (2000), encontra uma ambiguidade envolvendo essa ideia. Para o autor, a terra até pode não estar literalmente vazia, mas se encontrar desvalorizada, ainda que com potencialidade de reutilização para outros fins. Morgado (2005), ao tentar fugir dessa incerteza, esclarece 
que "vazios urbanos" são espaços preferencialmente não edificados e que estão ligados às infraestruturas urbanas, razão pela qual são relevantes e podem voltar a exercer funções sociais e urbanas na cidade.

Sousa (2010) por sua vez, é mais direto e afirma que o "vazio urbano" não é caracterizado pelo fato de a propriedade estar edificada ou não, mas, sim, por não apresentar uso, estar desafetado de função. É consequência dos processos de marginalização, degradação e decadência física, econômica e social. São espaços que aguardam por uma reutilização, uma vez que apresentam potenciais de uso. 0 referido autor ainda afirma que, nas últimas décadas, há um verdadeiro fenômeno, comum às grandes metrópoles mundiais, de esvaziamento de espaços urbanos centrais com a perda de boa parcela das suas funções produtivas, tornando-se obsoletos e disponíveis.

A partir de 1990 surgiram várias outras terminologias oriundas de reflexões teóricas de pesquisadores, os quais buscavam entender o processo de esvaziamento dos espaços urbanos (Clemente, 2012). Dentre estas, Borde (2006) destaca: as provenientes do francês, terrains désaffectés, terrains délaissés, vides urbains (terrenos em desuso, negligenciados e vazios urbanos respectivamente); do inglês, derelict land (terrenos abandonados), e a americana vacant land (terras devolutas).

Conforme Dittmar (2006, p. 14), "vazios urbanos" são os espaços construídos ou não, desocupados ou subutilizados, caracterizados como "[...] resíduos do crescimento urbano", resultantes, muitas vezes, de uma antiga atividade industrial. Janeiro $(2009$, p. 7) conceitua "vazios urbanos" como "[...] bolsas vazias na cidade, áreas destituídas, ausentes, silenciosas, onde aquilo que lá acontecia já não acontece ou onde nunca lá nada aconteceu".

Em um olhar debruçado sobre a cidade é possível perceber diversos espaços no seu interior com estas características: se encontram à espera de algo, para voltarem a fazer parte da cidade, tanto a nível social como econômico ou cultural. A degradação destas áreas também implica oportunidades que elas representam para uma regeneração urbana do local onde se inserem (Santos, 2011).

Apesar das potencialidades positivas, Portas (2000) ressalta a necessidade de as medidas de transformação dos vazios urbanos adotarem estratégias orientadas por autoridades competentes para tal, utilizando elementos bem definidos para a reestruturação do território, evitando efeitos perversos.

O planejamento e a gestão urbana dos vazios é uma tarefa que carece ser construída de acordo com vários fatores e de modo articulado entre vários atores (gestores públicos, comunidade, especialistas em urbanismo). É preciso identificar os problemas de cada região onde se encontra o espaço esvaziado, sentir o prático-sensível desses lugares, para, assim, direcionar as ações e potencializar seu uso, combatendo os problemas ali manifestados (Santana, 2006). Portanto, em áreas mais marginalizadas onde faltam moradias, criam-se habitações. Em áreas onde há altos índices de desemprego, criam-se locais que proporcionem oportunidades (lavanderias, casas de costura, cooperativas de reciclagem, espaços para artesanatos, etc.). Em áreas pouco arborizadas ou com poucos espaços de interação social, promove-se a criação de áreas verdes, parques e praças. Revitalizar esses terrenos e edifícios vacantes possibilita reverter os significados negativos a eles atribuídos, além de proporcionar o desenvolvimento da cidade, minimizando desigualdades sociais e espaciais (Borde, 2006).

Dittmar (2006) caminha nesse mesmo sentido e acrescenta que a morfologia urbana não se apresenta como uma simples imagem, nem a cidade como uma mera localização. Na verdade, ela deve ser analisada e discutida no sentido histórico, envolvendo os elementos que, combinados no tempo, produziram este ou aquele resultado. Também deve-se considerar o tanto que o desenvolvimento econômico influenciou e o modo de a cidade agir sobre o espaço social. Enfim, para discutir e analisar o papel da morfologia urbana, precisa-se abordá-la em todos os seus aspectos.

Santana (2006), contudo, ressalta que o processo de reocupação dos espaços encontra barreiras que se colocam à frente de qualquer planejamento, por mais pertinente que seja, que são aquelas impostas pela lógica do mercado que acabam por determinar o modo com o qual a cidade vai crescer e se modelar. Conforme a autora, o interesse de poucos agentes específicos, detentores de grandes áreas urbanas, prevalece sobre o de muitos, inclusive sob a forma de retenção de terras, gerando a formação de "vazios urbanos", com a finalidade de promover especulações de valor. 
Um planejamento urbano bem alinhado com a realidade que demanda intervenção exige a identificação dos problemas de cada região onde se encontra o espaço esvaziado, sentir o prático-sensível desses lugares para, desse modo, direcionar ações e potencializar usos combatendo os problemas ali manifestados, efetivando o direito à cidade.

\section{Direito à cidade como campo de pesquisa}

Antes de adentrar nos resultados e discussões da presente pesquisa, é necessário fazer menção ao campo de pesquisa relativo ao direito à cidade e sua relevância para estudos que buscam observar os fenômenos atuantes sobre o espaço urbano. Nesse sentido, vale destacar as lições de Lefebvre (2010) que, ao se dedicar à observação das formas, funções e estruturas (econômicas, políticas, culturais, etc.) da cidade, afirmou que é preciso que sejam promovidas reflexões teóricas sobre o urbano e o modo com o qual este atende às necessidades sociais básicas.

Entendimento similar pode ser retirado do discurso Castells (2009), quando o referido autor explicita o papel central que o Estado deve desempenhar nos processos de urbanização, o qual precisa ser norteado por uma teoria capaz de integrar análises dos espaços urbanos com as lutas e necessidades sociais preexistentes no cotidiano destes.

Todavia, como podemos delimitar a atual situação da cidade como espaço para efetivação de direitos? Harvey (2012), para dar resposta a este questionamento, critica o fato do direito à cidade, no instante atual, encontrar-se em uma situação que restringe a participação da sociedade como um todo nas discussões sobre sua estrutura. Para o autor, é preciso adotar o direito à cidade tanto como lema operacional quanto ideal político.

Castells (2009), a seu turno, cita que não é possível perceber uma fusão real entre os movimentos urbanos (estrutura de classes, formas espaciais relativas ao consumo, ações políticas) que visam convergir sobre aspectos referentes à realidade das cidades e suas urgências.

0 que se percebe é uma realidade na qual poucos (geralmente detentores de poder político) ditam como a cidade deve ser concebida. Consoante Lefebvre (2010), o duplo processo de industrialização e urbanização acaba por perder todo seu sentido quando a sociedade urbana deixa de ser o principal objetivo e finalidade.

Surge, portanto, uma necessidade de debater os aspectos sociais da realidade urbana, de entender a importância do conceito de Lefebvre (2010) acerca do "prático-sensível”. A partir dessa ideia, depreendese que o meio social será atingido diretamente pelas políticas implementadas nos espaços urbanos, pois a cidade sempre se relacionou com a sociedade em seu conjunto e isso impossibilita que uma visão simplista, independente, traga resultados positivos no momento em que se busca modificar a estrutura urbana.

A cidade não pode mais ser entendida como uma entidade filosófica, mas sim como uma morfologia resultante de situações cotidianas, práticas e sensíveis existentes desde as relações de vizinhança até os movimentos sociais. É essa forma de enxergar e pensar a cidade que acreditamos ser a mais adequada para promover mudanças em sua forma.

Percebendo o esvaziamento de algumas áreas públicas municipais e o não aproveitamento de outras, essa pesquisa busca entender a formação de "vazios urbanos" públicos, isto é, áreas públicas desprovidas de qualquer função que procure atender o "prático-sensível". Busca-se dar valor de uso aos espaços públicos da cidade de Campina Grande, Paraíba.

Nesse sentido, não basta apenas construir espaços públicos de modo inconsequente. É preciso entender os movimentos sociais de cada área onde irá ser realizada cada ação e os impactos resultantes destas. Em situações nas quais as reais necessidades não são observadas, percebe-se o esvaziamento de utilização de áreas públicas que, apropriadas por pequenos grupos marginalizados, tornam áreas relevantes em espaços subutilizados ou não utilizados. 
A presente pesquisa, tem como objetivo estudar o modo com o qual a Administração Pública se relaciona com áreas urbanas públicas, mais especificamente, quando o poder público deixa de utilizá-las em prol do coletivo e os impactos acarretados por essa omissão dentro dos diversos contextos urbanos. Busca-se investigar a existência do fenômeno dos "vazios urbanos" na cidade de Campina Grande, Paraíba, visando identificar se a gestão do espaço urbano atende ao interesse coletivo.

\section{Metodologia}

Conhecida como a Rainha da Borborema, Campina Grande é um município brasileiro localizado no Planalto da Borborema, segunda maior cidade do estado da Paraíba, formado por uma área de $593,026 \mathrm{~km}^{2}$, dos quais $340 \mathrm{~km}^{2}$ representam o perímetro urbano. De acordo com o Instituto Brasileiro de Geografia e Estatística (IBGE, 2019), a população estimada é de 409.731 e o município possui uma densidade demográfica de $648,31 \mathrm{hab} / \mathrm{km}^{2}$. 0 PIB per capita corresponde a $\mathrm{R} \$ 21.077,30$ e apresenta um IDH de 0,720 , o que denota que a cidade apresenta desenvolvimento mediano.

Conforme poderá ser observado nos resultados expostos, a existência de um maior número de "vazios urbanos" nas áreas periféricas apresenta correlação direta com o fato de serem espaços carentes, marginalizados. A pobreza em Campina Grande, e como em outros grandes centros, é empurrada para as zonas periféricas. É neste contexto que a presente pesquisa buscou mapear e classificar os imóveis públicos esvaziados de função pública.

Para tanto, e de acordo com conceitos teóricos trabalhados anteriormente, foram criadas categorias com base nas funções, usos e edificações de imóveis públicos (Quadro 1). Estas categorias serviram para proceder com a classificação dos vazios urbanos encontrados neste mapeamento. Consoante Clemente (2012), dentre praticamente todas as classificações que podem ser estudadas nos referenciais teóricos disponíveis, observa-se que há um ponto comum: a característica atual de improdutividade das áreas esvaziadas.

Quadro 1 - Classificação dos imóveis públicos esvaziados

\begin{tabular}{|c|c|c|c|c|}
\hline \multirow{2}{*}{ CATEGORIA } & \multirow{2}{*}{ FUNÇÃO } & \multicolumn{2}{|c|}{ USO } & \multirow{2}{*}{ EDIFICAÇÃO } \\
\cline { 3 - 4 } & & TOTAL & PARCIAL & \\
\hline Imóvel não utilizado & NÃO POSSUI & NÃO & NÃO & Foi edificado \\
\hline Imóvel desocupado & NÃO POSSUI & NÃO & NÃO & Não foi edificado \\
\hline Imóvel subutilizado & POSSUI & NÃO & SIM & Foi edificado \\
\hline
\end{tabular}

Fonte: Elaboração própria com base em Clemente (2012).

Conforme ilustrado abaixo (Figura 1), a primeira categoria é composta por imóveis públicos desafetados ou não utilizados. São tanto as edificações que se encontram sem uso quanto aquelas que, por apresentarem alto grau de deterioração, são consideradas como ruínas, apresentando-se impossibilitadas de receber funções antes de que se proceda com uma revitalização do espaço com uma infraestrutura básica indispensável.

A segunda categoria, por sua vez, é composta pelos imóveis públicos desocupados, isto é, aqueles que se encontram literalmente vagos ou quando possuam, no máximo, alicerces de construções abandonados. Os imóveis subutilizados configuram a terceira categoria. Assim serão considerados os espaços que não estejam sendo totalmente aproveitados. Temos como exemplos desses imóveis aqueles que estão sendo parcialmente utilizados, como edifícios com mais de um piso onde apenas uma parte é utilizada, ou como grandes áreas que foram parcialmente utilizadas em construções. 

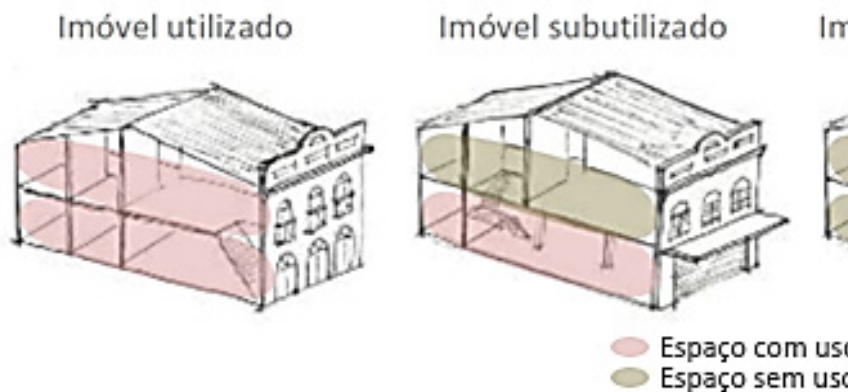

Figura 1 - Representação visual dos vazios urbanos. Fonte: Clemente (2012) adaptado pelo autor.

Também foram verificadas, em cada um dos imóveis públicos que se encaixaram nas três grandes categorias acima descritas, as características referentes às dimensões e ao estado de conservação. A relevância desse levantamento se encontra: a) nas possibilidades de uso que podem surgir após a identificação de uma necessidade coletiva que se adequa a determinado imóvel atualmente vazio; b) na possibilidade de reutilizar ou revitalizar imóveis com infraestrutura básica já construída.

A coleta de dados se deu no período de julho a dezembro de 2017. A validação das informações, mais especificamente, a verificação se os imóveis mapeados realmente pertencem ao município, foi realizada junto ao Cadastro Imobiliário da PMCG. Além de visitas in loco, o mapeamento desses espaços foi realizado com o auxílio dos softwares Google Maps e Google Earth Pro. Estas ferramentas também foram úteis para proceder com a medição $\left(\mathrm{em}^{2}\right)$ das áreas dos espaços vazios sempre que a Prefeitura Municipal de Campina Grande não disponibilizou ou afirmou desconhecer tal informação.

\section{Resultado e discussões}

O mapeamento de imóveis públicos inseridos nas condições metodológicas acima traçadas inicia-se na parte interna do município de Campina Grande (centro) e vai até os bairros localizados nas regiões mais periféricas. Desse modo, os dados obtidos na observação de campo serão apresentados seguindo essa lógica.

A princípio, tratando dos imóveis públicos não utilizados, foi possível identificar 10 espaços esvaziados de função, mas edificados (Figura 2 e Quadro 2). Vale destacar que são excluídas, todavia, desta categoria, as edificações não utilizadas que foram recém construídas ou reformadas, nas quais ainda não está sendo desenvolvida nenhuma atividade (Clemente, 2012).

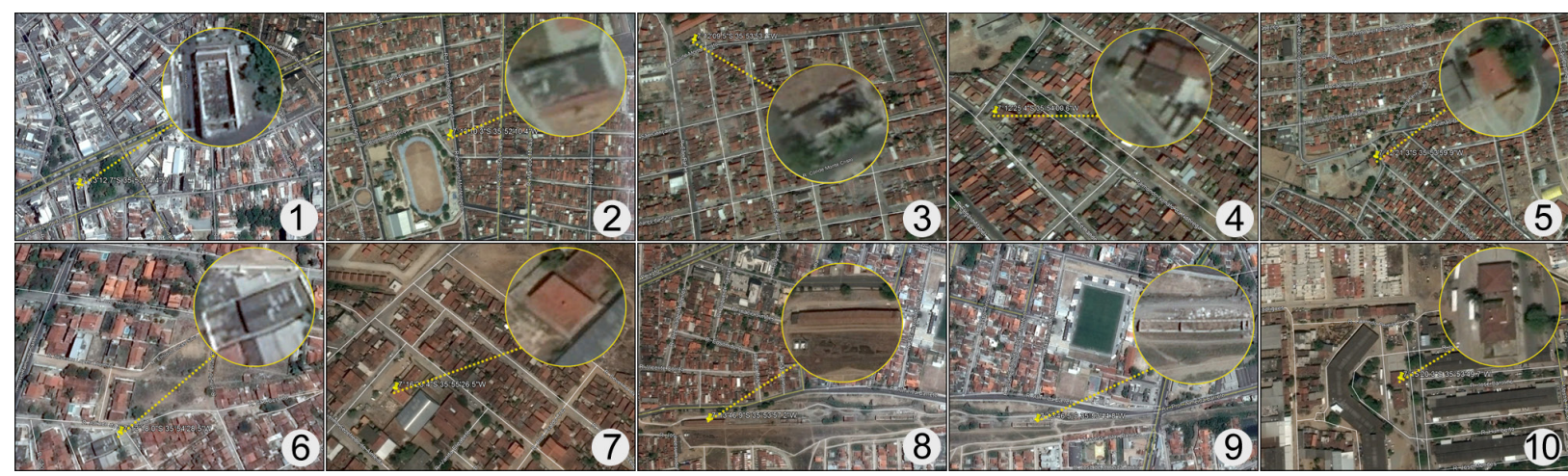

Figura 2 - Imagens de satélite dos imóveis públicos não utilizados. Fonte: Elaborado pelo autor com base no Google Earth Pro. 
Quadro 2 - Usos anteriores, dimensões e localização de imóveis não utilizados

\begin{tabular}{|c|c|c|c|}
\hline IMÓVEL No & USO ANTERIOR & TAMANHO $\left(\mathbf{m}^{2}\right)$ & COORDENADAS \\
\hline 1 & Cinema & $860 \mathrm{~m}^{2}$ & $7^{\circ} 13^{\prime} 12.7^{\prime \prime} \mathrm{S} 35^{\circ} 53^{\prime} \mathrm{O} 4.4^{\prime \prime} \mathrm{W}$ \\
\hline 2 & Cozinha comunitária & $150 \mathrm{~m}^{2}$ & $7^{\circ} 13^{\prime} 10.3^{\prime \prime} \mathrm{S} 35^{\circ} 52^{\prime} 10.4^{\prime \prime} \mathrm{W}$ \\
\hline 3 & Unidade Escolar & $1.000 \mathrm{~m}^{2}$ & $7^{\circ} 12^{\prime} 09.5^{\prime \prime} \mathrm{S} 35^{\circ} 53^{\prime} 53.1^{\prime \prime} \mathrm{W}$ \\
\hline 4 & Lavanderia Municipal & $160 \mathrm{~m}^{2}$ & $7^{\circ} 12^{\prime 2} 25.4^{\prime \prime} \mathrm{S} 35^{\circ} 54^{\prime} \mathrm{O} 0.6^{\prime \prime} \mathrm{W}$ \\
\hline 5 & Cozinha Comunitária & $380 \mathrm{~m}^{2}$ & $7^{\circ} 12^{\prime} 21.3^{\prime \prime} \mathrm{S} 35^{\circ} 53^{\prime} 59.9^{\prime \prime} \mathrm{W}$ \\
\hline 6 & Lavanderia Municipal & $600 \mathrm{~m}^{2}$ & $7^{\circ} 13^{\prime} 18.0^{\prime \prime} \mathrm{S} 35^{\circ} 54^{\prime} 28.5^{\prime \prime} \mathrm{W}$ \\
\hline 7 & Cozinha Comunitária & $175 \mathrm{~m}^{2}$ & $7^{\circ} 16^{\prime} 23.4^{\prime \prime} \mathrm{S} 35^{\circ} 55^{\prime} 26.5^{\prime \prime} \mathrm{W}$ \\
\hline 8 & Armazém & $7^{\circ} 13^{\prime} 46.9^{\prime \prime} \mathrm{S} 35^{\circ} 53^{\prime} 57.2^{\prime \prime} \mathrm{W}$ \\
\hline 9 & Galpão & $7^{\circ} 13^{\prime} 46.5^{\prime \prime} \mathrm{S} 35^{\circ} 53^{\prime} 44.8^{\prime \prime} \mathrm{W}$ \\
\hline 10 & Restaurante Popular & $765 \mathrm{~m}^{2}$ & $7^{\circ} 15^{\prime} 20.3^{\prime \prime} \mathrm{S} 35^{\circ} 53^{\prime} 49.7^{\prime \prime} \mathrm{W}$ \\
\hline
\end{tabular}

Fonte: Elaborado pelo autor com base em dados da pesquisa (2018).

Foi encontrado um total de dez unidades espalhadas pelos bairros: Jeremias ( 3 unidades), Centro, José Pinheiro, Pedregal, Quarenta (2 unidades), Jardim Paulistano e Acácio Figueiredo. Percebe-se que são características comuns a esses imóveis: estão localizados em bairros periféricos e antes possuíam uma função específica, de baixo custo e de extrema relevância para as comunidades que os cercam. É o caso de antigas lavanderias municipais, cozinhas comunitárias, restaurantes populares e outras construções.

O cessar da prestação desses serviços por parte do poder público municipal reside em três fatores: falta de manutenção da infraestrutura básica (cinema, lavanderias, unidade escolar), licitações interrompidas ou não realizadas (cozinhas comunitárias e restaurante popular) e desativação de atividades antes comuns (galpão e armazém próximos à linha férrea desativada antes utilizados para estocar produtos que agora são transportados através de rodovias).

Em razão da não utilização dessas propriedades, vem ocorrendo um desgaste natural das estruturas. Este processo acaba por ser acelerado pela deterioração ocasionada pela ação de vândalos e o furto de partes das construções (portas, janelas e componentes das instalações elétricas).

Partindo para os imóveis públicos municipais categorizados como desocupados, foram mapeadas 5 unidades dentro do perímetro urbano de Campina Grande, conforme Figura 3 e Quadro 3 a seguir:

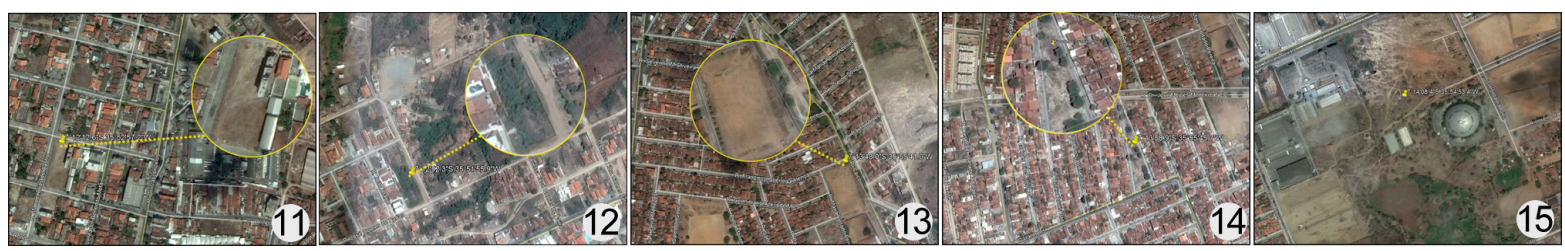

Figura 3 - Imagens de satélite imóveis públicos desocupados. Fonte: Elaborado pelo autor com base no Google Earth Pro.

Quadro 3 - Usos anteriores, dimensões e localização de imóveis desocupados

\begin{tabular}{|c|c|c|c|}
\hline IMÓVEL N & USO ANTERIOR & TAMANHO $\left(\mathbf{m}^{\mathbf{2}}\right)$ & COORDENADAS \\
\hline 11 & Não Identificado & $3.960 \mathrm{~m}^{2}$ & $7^{\circ} 12^{\prime} 12.6^{\prime \prime} \mathrm{S} 35^{\circ} 52^{\prime} 57.2^{\prime \prime} \mathrm{W}$ \\
\hline 12 & Não Identificado & $2.460 \mathrm{~m}^{2}$ & $7^{\circ} 12^{\prime} 52.3^{\prime \prime} \mathrm{S} 35^{\circ} 51^{\prime} 55.9^{\prime \prime} \mathrm{W}$ \\
\hline 13 & Não Identificado & $6.485 \mathrm{~m}^{2}$ & $7^{\circ} 13^{\prime} 48.0^{\prime \prime} \mathrm{S} 35^{\circ} 55^{\prime} 41.0^{\prime \prime} \mathrm{W}$ \\
\hline 14 & Não Identificado & $3.010 \mathrm{~m}^{2}$ & $7^{\circ} 13^{\prime} 58.9^{\prime \prime} \mathrm{S} 35^{\circ} 55^{\prime} 45.7^{\prime \prime} \mathrm{W}$ \\
\hline 15 & Não Identificado & $200.000 \mathrm{~m}^{2}$ & $7^{\circ} 12^{\prime} 21.3^{\prime \prime} \mathrm{S} 35^{\circ} 53^{\prime} 59.9^{\prime \prime} \mathrm{W}$ \\
\hline
\end{tabular}

Fonte: Elaborado pelo autor com base em dados da pesquisa (2018).

Estes imóveis desocupados foram encontrados nos bairros: Jardim Tavares, Louzeiro, Malvinas ( 2 unidades) e Dinamérica. Reiteramos que se entende por desocupados aqueles espaços que pertencem ao município de Campina Grande e estão marcados pela total improdutividade. São aqueles que se encontram literalmente vagos, sem nenhuma edificação e sem exercer nenhuma função que traga benefícios à coletividade. 
Destacamos que os espaços desocupados frequentemente são alvos de invasões por parte de comunidades carentes. Este embate social entre o poder público proprietário e indivíduos excluídos, com direito à habitação negado, é facilmente observado no imóvel no 15 , entorno do ginásio esportivo "O Meninão", o qual, sem nenhuma finalidade atribuída, encontra-se negligenciado e tomado por ocupações irregulares.

Diante desse cenário, é possível perceber uma série de problemas urbanos concentrados em apenas um local: falta de saneamento básico, infraestrutura básica, falta de serviços públicos. Surge o questionamento: por que não utilizar essas áreas para fins habitacionais e acabar de vez com o problema? Afinal, nunca se teve notícia de nenhum projeto para a utilização dessa imensa área. Logo, legitimar a utilização desses terrenos deveria ser considerado.

Quanto aos imóveis subutilizados (Figura 4 e Quadro 4 ), foram localizados um total de 4 unidades espalhadas pelos bairros: Centro ( 2 unidades), José Pinheiro e Louzeiro.

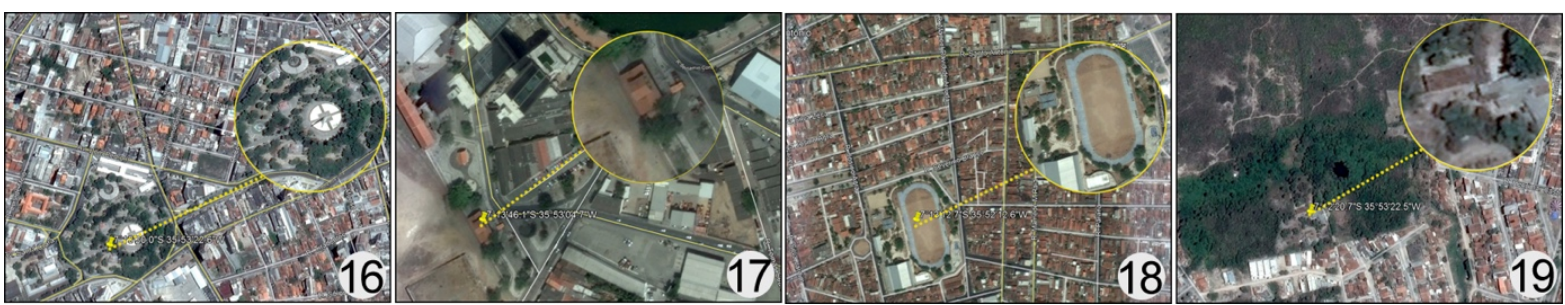

Figura 4 - Imagens de satélite imóveis públicos subutilizados. Fonte: Elaborado pelo autor com base no Google Earth Pro.

Quadro 4 - Usos anteriores, dimensões e localização de imóveis subutilizados

\begin{tabular}{|c|c|c|c|}
\hline IMÓVEL N & USO PARCIAL & TAMANHO $\left.\mathbf{( m}^{\mathbf{2}}\right)$ & COORDENADAS \\
\hline 16 & Área verde e de lazer & $35.620 \mathrm{~m}^{2}$ & $7^{\circ} 13^{\prime} 20.0^{\prime \prime} \mathrm{S} 35^{\circ} 53^{\prime} 22.6^{\prime \prime} \mathrm{W}$ \\
\hline 17 & Museu & $2.915 \mathrm{~m}^{2}$ & $7^{\circ} 13^{\prime} 46.1^{\prime \prime} \mathrm{S} 35^{\circ} 53^{\prime} 04.7^{\prime \prime} \mathrm{W}$ \\
\hline 18 & Parque esportivo & $29.500 \mathrm{~m}^{2}$ & $7^{\circ} 13^{\prime} 12.7^{\prime \prime} \mathrm{S} 35^{\circ} 52^{\prime} 12.6^{\prime \prime} \mathrm{W}$ \\
\hline 19 & Área verde e de lazer & $180.000 \mathrm{~m}^{2}$ & $7^{\circ} 12^{\prime} 20.7^{\prime \prime} \mathrm{S} 35^{\circ} 53^{\prime} 22.5^{\prime \prime} \mathrm{W}$ \\
\hline
\end{tabular}

Fonte: Elaborado pelo autor com base em dados da pesquisa (2018).

Assim foram considerados aqueles imóveis em que há uma potencialidade de uso muito maior de que a atualmente apresentada pela Administração Pública, seja pelo não aproveitamento do total da área disponível, seja pelo fato de os cidadãos encontrarem-se impedidos de usufruir plenamente do espaço, tendo em vista fatores sociais como criminalidade (Parque Evaldo Cruz e Vila Olímpica Plínio Lemos, imóveis no 16 e 18, respectivamente) ou fatores físicos, como má conservação.

Na zona norte do município está localizado o Jardim Botânico Municipal do Louzeiro (imóvel no 19), área verde de preservação criada pela Lei no $6.250 / 2015$ de $500.000 \mathrm{~m}^{2}$, em que apenas $36 \%$ (180.000 $\left.\mathrm{m}^{2}\right)$ pertence ao poder público e que contém uma enorme riqueza vegetal. A região onde fica localizada a Mata do Louzeiro já era considerada como uma área de preservação permanente pela Lei Orgânica do Município de Campina Grande. A transformação desse espaço em um Jardim Botânico nos parece ser adequado e está alinhado com os novos conceitos de cidade sustentável. Entretanto, passados dois anos da promulgação da Lei no 6.250/2015, o espaço ainda se encontra subutilizado e sem a infraestrutura mínima necessária para efetivação dos objetivos idealizados pelo poder público.

Em números gerais, foi encontrado um total de 19 imóveis públicos de propriedade do município de Campina Grande esvaziados de qualquer função pública. Destes, 10 são imóveis não utilizados, 4 constituem imóveis subutilizados e outros 5 são aqueles desocupados. Como representação visual das informações acima elencadas, elaboramos a Figura 5, a qual reúne todos os "vazios urbanos" encontrados em nossa pesquisa e suas respectivas localizações por bairros do município de Campina Grande. 


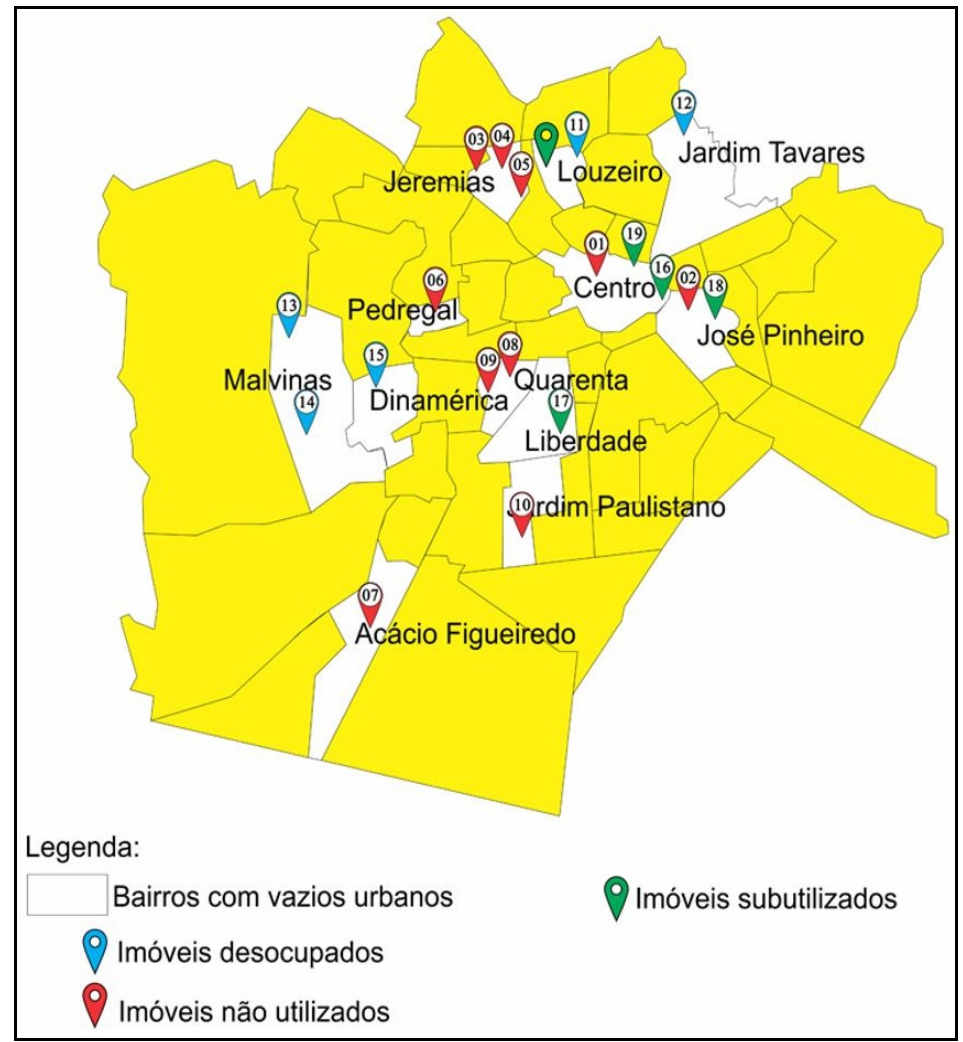

Figura 5 - Localização dos imóveis públicos vazios por bairro. Fonte: Elaborado pelo autor (2018) com base em dados obtidos na pesquisa.

No momento em que partimos para os cálculos das áreas públicas municipais consideradas como vazios urbanos (Tabela 1), chegamos a um total de $469.910 \mathrm{~m}^{2}$.

Tabela 1 - Áreas dos "vazios urbanos" públicos

\begin{tabular}{cc}
\hline CLASSIFICAÇÃO & ÁREA $\left(\mathrm{m}^{2}\right)$ \\
\hline Não utilizados & $5.960 \mathrm{~m}^{2}$ \\
Subutilizados & $248.035 \mathrm{~m}^{2}$ \\
Desocupados & $215.915 \mathrm{~m}^{2}$ \\
Total & $469.910 \mathrm{~m}^{2}$ \\
\hline
\end{tabular}

Fonte: Elaborado pelo autor (2018) com base em dados obtidos na pesquisa.

Contudo, esses números devem ser analisados com cautela. Em verdade, os imóveis não utilizados (encontrados em maior número na pesquisa) representam a menor parcela desses espaços, pois, em geral, são bens públicos que eram destinados a atividades mais simples (apesar de extremamente necessárias) do dia a dia das comunidades e que não exigem uma área muito grande para sua implementação.

Já o total da área dos imóveis subutilizados corresponde a $248.035 \mathrm{~m}^{2}$. Esses espaços, por sua vez, são caracterizados precipuamente por grandes áreas que não são completamente utilizadas, tendo seus potenciais de uso subaproveitados. Nesse montante, merece destaque o imóvel no 19 , Jardim Botânico do Louzeiro, o qual apresenta $180.000 \mathrm{~m}^{2}$ de área pública, correspondente a um pouco mais de $72,5 \%$ do total da área dos subutilizados. 0 total das áreas somadas dos imóveis desocupados é de $215.915 \mathrm{~m}^{2}$. Desse espaço, $200.000 \mathrm{~m}^{2}$ (mais de 92,6\%) pertencem à área circunvizinha aos Ginásio Esportivo O Meninão. 


\section{Considerações finais}

Diante desse cenário, em que é possível detectar a presença de diversos espaços considerados como "vazios urbanos", surge a necessidade de entender como eles nascem, os prejuízos causados à sociedade e de que modo é possível devolvê-los à dinâmica urbana. Ocorre que, quando essas áreas esvaziadas pertencem ao Estado, o olhar deve abranger o modo como o poder público atua e as regras que regem essa atuação.

Na busca por "vazios urbanos" no município de Campina Grande, foi descoberta com uma realidade alarmante: 19 imóveis públicos esvaziados localizados dentro do perímetro urbano. 0 objetivo desta pesquisa, de investigar a presença desse fenômeno no município acima citado, foi alcançado. Com isso, também foi possível realizar um verdadeiro mapeamento de imóveis públicos encontrados nessas condições, identificar suas realidades e classificá-los de acordo com elas.

Esses resultados, de maneira geral, denotam a necessidade de se promover políticas públicas que objetivem obstar a formação de novos esvaziamentos e utilizar esses espaços de acordo com as necessidades dos indivíduos que ali habitam. Para tanto, deve-se compreender os movimentos urbanos, o conceito "prático-sensível" de Lefebvre (2010), de modo que as medidas apresentem altos valores de uso para a população.

Notadamente, quanto mais o poder público buscar alcançar uma real efetivação do interesse público, mais a cidade será estruturada e pensada como um grande espaço de implementação de políticas públicas. Uma das funções precípuas do Estado é buscar reduzir as desigualdades sociais que surgem como resultados de fenômenos do mercado. Por conseguinte, cabe a ele pensar o urbano de acordo com as necessidades daqueles que estão em situação menos privilegiada. É assim que os espaços públicos devem ser pensados. Imagine que, em áreas marginalizadas, onde o acesso à cultura é negado, exista um imóvel público desfuncionalizado, o qual poderia estar servindo a esse fim. Esse olhar atencioso deve fazer parte do cotidiano do gestor público para que situações como essa não ocorram.

Nesse sentido, aos imóveis subutilizados basta maximizar suas potencialidades, explorar os totais de suas áreas, revitalizá-los para que a população volte a deles se apropriar. Para os imóveis não utilizados, por sua vez, é necessário entender a dinâmica da área da cidade na qual ele está inserido (o prático-sensível) e formular ações que os deem valor. De maneira geral, foi possível detectar que a simples reutilização de suas funções anteriores já seria valiosa para as comunidades circunvizinhas. Essa ideia também é perfeitamente aplicável aos imóveis públicos desocupados. É necessário entender o contexto no qual o espaço esvaziado está inserido para promover sua adequada ocupação.

Além da urgente necessidade de produção de ferramentas legais que obriguem o gestor público a evitar que "vazios urbanos" sejam formados por bens imóveis públicos, é necessário que sejam criados canais eficazes de articulação entre o Estado e o cidadão para que as utilizações e reutilizações dos espaços públicos sejam geradoras de reais ganhos para a sociedade.

Em dois próximos estudos, já em desenvolvimento, os dados obtidos através do mapeamento aqui apresentado serão utilizados a fim de compreender as relações entre as comunidades existentes no entorno desses espaços esvaziados de funções públicas. O objetivo é, ao final, apresentar ao poder público municipal, através da aplicação de questionários, um levantamento dos usos mais adequados de acordo com a visão dos próprios cidadãos. Afinal, vale destacar a lição de Portas (2000) ao destacar a ideia de que reside em todo "vazio urbano" grandes oportunidades de mudança, de renovação funcional ou ambiental.

\section{Referências}

Abe, N. C. (2008). Notas sobre a inaplicabilidade da função social à propriedade pública. Revista Brasileira de Direito Constitucional, 7(18), 135-154. http://dx.doi.org/10.25109/2525-328X.v.7.n.18.2008.314. 
Borde, A.P.L. (2006). Vazios urbanos: perspectivas contemporâneas (Tese de doutorado). Faculdade de Arquitetura e Urbanismo, Universidade Federal do Rio de Janeiro. Rio de Janeiro.

Brasil. (1988, 5 de outubro). Constituição da República Federativa do Brasil de 1988. Brasília: Diário Oficial da União.

Brasil. (2001, 11 de julho). Lei n. 10.257, de 10 de julho de 2001. Regulamenta os arts. 182 e 183 da Constituição Federal, estabelece diretrizes gerais da política urbana e dá outras providências. Brasília: Diário Oficial da União, seção 1.

Campina Grande. (2006, 9 de outubro). Lei Complementar n. 003, de 8 de outubro de 2006. Promove a revisão do Plano Diretor do Município de Campina Grande. Campina Grande: Diário Oficial do Município, seção 1.

Carvalho, W. C. (2012). Bens dominicais: um anacronismo na administração pública. Revista Controle: Doutrinas e Artigos, 10(2), 158-169. http://dx.doi.org/10.32586/rcda.v10i2.240.

Castells, M. (2009). A questão urbana (4. ed.). São Paulo: Paz e Terra.

Clemente, J. C. (2012). Vazios urbanos e imóveis subutilizados no centro histórico tombado da cidade de João Pessoa PB (Dissertação de mestrado). Universidade Federal da Paraíba, João Pessoa.

Di Pietro, M. S. Z. (2006). Função social da propriedade pública. Revista Eletrônica de Direito do Estado, (6), 1-13.

Dittmar, A. C. C. (2006). Paisagem e morfologia de vazios urbanos: análise da transformação dos espaços residuais e remanescentes urbanos ferroviários em Curitiba - PR (Dissertação de mestrado). Pontifícia Universidade Católica do Paraná, Curitiba.

Harvey, D. (2012). 0 direito à cidade. Lutas Sociais, (29), 73-89.

Instituto Brasileiro de Geografia e Estatística - IBGE (2019). População Estimada. Rio de Janeiro: IBGE.

Janeiro, P. A. (2009). Cheios inúteis: a imagem do vazio na cidade. Artitextos, (8), 181-193. Recuperado em 28 de dezembro de 2017, de http://hdl.handle.net/10400.5/1488

Lefebvre, H. (2010). O direito a cidade (5. ed.). São Paulo: Centauro.

Morgado, S. (2005). Protagonismo de la ausencia, Interpretación urbanística de la formación metropolitana de Lisboa desde lo desocupado (Tese de doutorado). Universidade Politécnica da Catalunha, Catalunha.

Portas, N. (2000). Do vazio ao cheio: vazios e o planejamento das cidades (Caderno de Urbanismo, No. 2). Rio de Janeiro: SMU. Recuperado em 28 de dezembro de 2017, de www.rio.rj.gov.br/smu

Santana, L. S. (2006). Os vazios urbanos nos centros de cidades como lugar para habitação de interesse social: o caso de Maceió/AL (Dissertação de mestrado). Faculdade de Arquitetura e Urbanismo, Universidade Federal de Alagoas, Maceió.

Santos, S. C. S. (2011). Espaços urbanos expectantes como oportunidades para a requalificação: entre a cidade e o rio (envolvente da Cordoaria) (Dissertação de mestrado). Universidade Técnica de Lisboa, Lisboa.

Sousa, C. A. (2010). Do cheio para o vazio: metodologia e estratégia na avaliação de espaços urbanos obsoletos (Dissertação de mestrado). Universidade de Lisboa, Lisboa.

Editor: Rodrigo Firmino

Recebido: Nov. 25, 2019

Aprovado: Fev. 27, 2020 